\title{
Shainin Methodology: An Alternative or an Effective Complement to Six Sigma?
}

\author{
DOI: 10.12776/QIP.V19I2.580
}

\author{
Jan Kosina \\ Received 6 June 2015, Accepted 17 October 2015, Published 31 December 2015
}

\begin{abstract}
Purpose: The purpose of this paper is to provide a brief overview of Six Sigma and Shainin RedX ${ }^{\circledR}$ methodology and to propose the modification of Six Sigma methodology in order to achieve the improved efficiency of DMAIC in the diagnostic journey using some of the approaches of Shainin $\operatorname{RedX}^{\mathbb{B}}$ methodology.
\end{abstract}

Methodology/Approach: The diagnostic journey of Six Sigma has been revised by bringing key elements of Shainin $\operatorname{RedX}^{\circledR}$ methodology into DMAIC: task domain character of the method, focus on the dominant root-cause, use of the progressive elimination method and the application of a problem-solving strategy.

Findings: This paper presents a proposal of DMAIC framework modification using selected tools and procedures of Shainin $\operatorname{RedX} X^{\circledR}$ methodology in the diagnostic phase.

Research Limitation/implication: Although the improved methodology is used in the environment of the automotive supplier, in this paper, practical examples are not included in order not to violate the licensing rules applied by Shainin LLC.

Originality/Value of paper: The contribution of this article is the proposal of modified methodology, which should improve the effectiveness of problemsolving.

Category: Conceptual paper

Keywords: DMAIC; problem-solving; quality improvement; reduction of process variation; Shainin; Shainin $\operatorname{RedX}{ }^{\circledR}$; Six Sigma 


\section{INTRODUCTION}

The demands placed on an organization in today's global business environment are driven by customer satisfaction as well as the fulfilment of the expectations of stakeholders regarding cost reduction, improving business performance and maintaining a competitive advantage. An effective quality assurance system of a company consists of three key elements: quality planning, quality control and quality improvement (Juran and De Feo, 2010). One of the key factors in meeting the above-mentioned business expectations is quality improvement, the continuous improvement of quality built into the product along with the quality of the processes related to designing and manufacturing the product.

Quality improvement activities in manufacturing are in many cases focused on the reduction of process variation. Process variation is a critical factor of process stability and therefore the cost effectiveness of the process. There are two ways to reduce process variation: a) to identify and control the root-cause and b) to decrease the sensitivity of the process to the source of the variation.

Primarily the main goal of each activity designed to achieve an improvement in process variation is to identify the root-cause by using a problem-solving methodology. In the second case, we must identify varying process inputs, process characteristics whose values change in the related process without intervention. In such cases, the Robust Parameter Design could be used as an alternative to decrease the variation of the process by reducing the sensitivity to the variation source. This means finding the level of the varying inputs which leads to optimal process variation (Tosenovsky, Tosenovsky and Kudelka, 2013). Statistical Engineering (Steiner and MacKay, 2005) provides seven ways to achieve process variation reduction, from these we will outline five methods of improvement which can be used for a direct reduction of process variation:

- Identification and correction of a dominant root-cause;

- Desensitizing the process variation in a dominant root-cause;

- Feed-forward control to reduce the effect of the dominant root-cause;

- Feedback control based on the prediction of the process output coming out of the trend of previously measured output values;

- The increase of process robustness to cause variation, this means reducing the effect of the unknown dominant cause using the change of the fixed inputs.

\section{SIX SIGMA AND SHAININ REDX ${ }^{\circledR}$ METHODOLOGY}

Several strategies of quality improvement have been developed in order to define a methodology for problem-solving. The most often used methodology for improvement activities is Six Sigma. Statistically, the target of Six Sigma is to center the process mean to the target value and to reduce process variation. The 
role of Six Sigma is to improve quality using data analysis that leads to identification of the root-cause and the consecutive implementation of corrective measures. One of the Six Sigma definitions states according to (Linderman et al., 2003) "Six Sigma is an organized and systematic method for strategic process improvement and new product and service development that relies on statistical methods and the scientific method to make dramatic reductions in customer defined defect rates".

An alternative to Six Sigma - Shainin $\operatorname{RedX}^{\circledR}$ methodology - is based on the firm prerequisite of the existence of a dominant root-cause. A dominant root-cause is a root-cause having the largest effect on process variation. The assumption of there being a dominant root-cause arises from the application of the Pareto principle to the causes of variation. Shainin methodology is used by leading companies within the automotive sector as an effective tool for problem-solving (Wortham, 2008; Bovenzi et al., 2010; Schmidt, 2012).

If we compare the structure of both methodologies (Figure 1) we will find both consist of the diagnostic journey and the remedial journey (Juran and De Feo, 2010). The diagnostic phase as the first part of a problem-solving method goes from failure symptom to verified root-cause. The second phase - remedial journey - is the path leading to the implementation of an efficient solution.

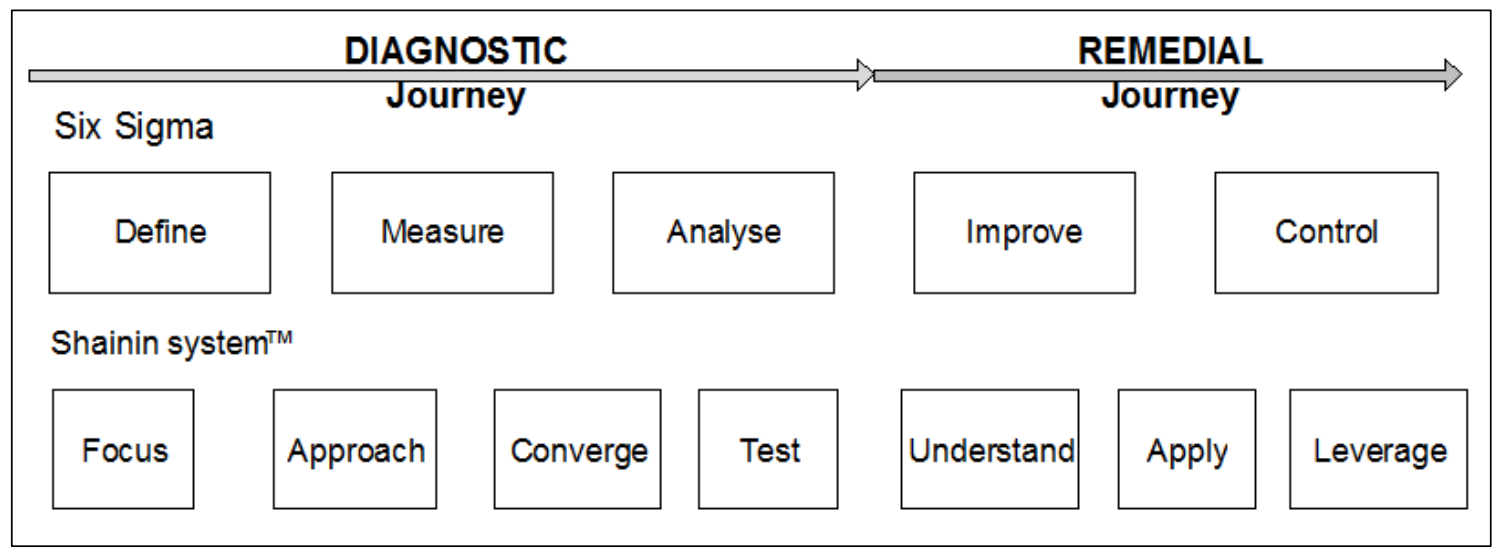

Figure 1 - Diagnostic and Remedial Journey

\subsection{Six Sigma}

The aim of Six Sigma methodology is to provide a structured approach to managing improvement activities. Primary structure is represented by the DMAIC framework (Define-Measure-Analyze-Improve-Control) used in process improvement. An alternative framework in the form of DMADV (Define-Measure-Analyse-Design-Verify) is used in product or service design improvement. In addition Six Sigma provides a set of tools and techniques which are intended to be applied in the course of the diagnostic and remedial journey. In other words DMAIC provides a methodological guide for problem-solving as a key element of improvement projects. To be more specific DMAIC defines a general framework used in order to solve the problem but does not refer to a 
clearly defined step-by-step structured problem-solving process. Consequently Six Sigma rather refers to the collection of quality tools and methods.

Six Sigma DMAIC was originally developed as a method for process variation reduction but the later development of the methodology led to its recent application in generic problem-solving and approach to improvement. Actions aimed at achieving improvement are derived from detected relationships between process input(s) and output. The method prescribes that problems are clearly described by quantified parameters. Six Sigma underscores the application of quantitative metrics, such as process variation measurements, critical-to-quality metrics, critical-to-process parameters, defect rates as well as traditional quality measures such as process capability. These metrics are used to define improvement goals and they are followed up during the entire life time of the improvement project.

\subsection{Shainin}

Shainin RedX ${ }^{\circledR}$ methodology was developed by Dorian Shainin from the $1950 \mathrm{~s}$ to the 1990s. The main difference between Shainin's approach to problemsolving and traditional problem-solving methodology is the convergent approach used to identify a root-cause, the so called Effect to Cause (Y to X). To apply the convergent approach it is absolutely necessary to understand the output $\mathrm{Y}$. Knowledge of the product and related processes, symptoms of failure as well as the contrast between good and bad parts are key elements in understanding the output Y. The output Y must be a measurable technical parameter with a clear relation to the physics of the failure - this defines the output we want to improve - Green $\mathrm{Y}^{\circledR}$. The progressive and convergent strategy is a crucial component in identifying the potential root-causes (Xs) by deep investigation of the parts (so called "talking to the parts"), the elimination of suspects and the comparison of good and bad parts along with finding extremes and contrasts. The potential causes $-\operatorname{RedX}^{\circledR}$ candidates - are tested using efficient confirmation methods.

$\operatorname{RedX}^{\circledR}$ paradigm - the key assumption of the whole methodology is based on the strong belief that there is always a dominant cause of variation. This statement is based on the application of the Pareto principle to the causes of the variation (Figure 2). Generally, the variation of the output is caused by the variation of several inputs.

We can express the variance of the output $\mathrm{Y}$ as

$\sigma(y)^{2}=f\left[\sigma(x)^{2}\right]$

$\sigma(y)^{2}=A_{1}^{2} \sigma_{x_{1}}^{2}+A_{2}^{2} \sigma_{x_{2}}^{2}+\cdots A_{12}^{2} \sigma_{x_{1}}^{2} \sigma_{x_{2}}^{2}+\cdots \varepsilon^{2}$

By the application of the Pareto principle we can define the contribution of the $\mathrm{Xs}$ - process inputs - to the $\Delta \mathrm{Y}$ - increment of the output (Figure 2). Following Shainin's philosophy there are no more than three root-causes playing a 
significant role: the dominant cause of the variation is called $\operatorname{RedX} X^{\circledR}$, the two other main causes are called Pink $X ®$ and Pale Pink $X ®$. RedX ${ }^{\circledR}$ can be a single variable or an interaction between separate variables (Shainin, 1993).

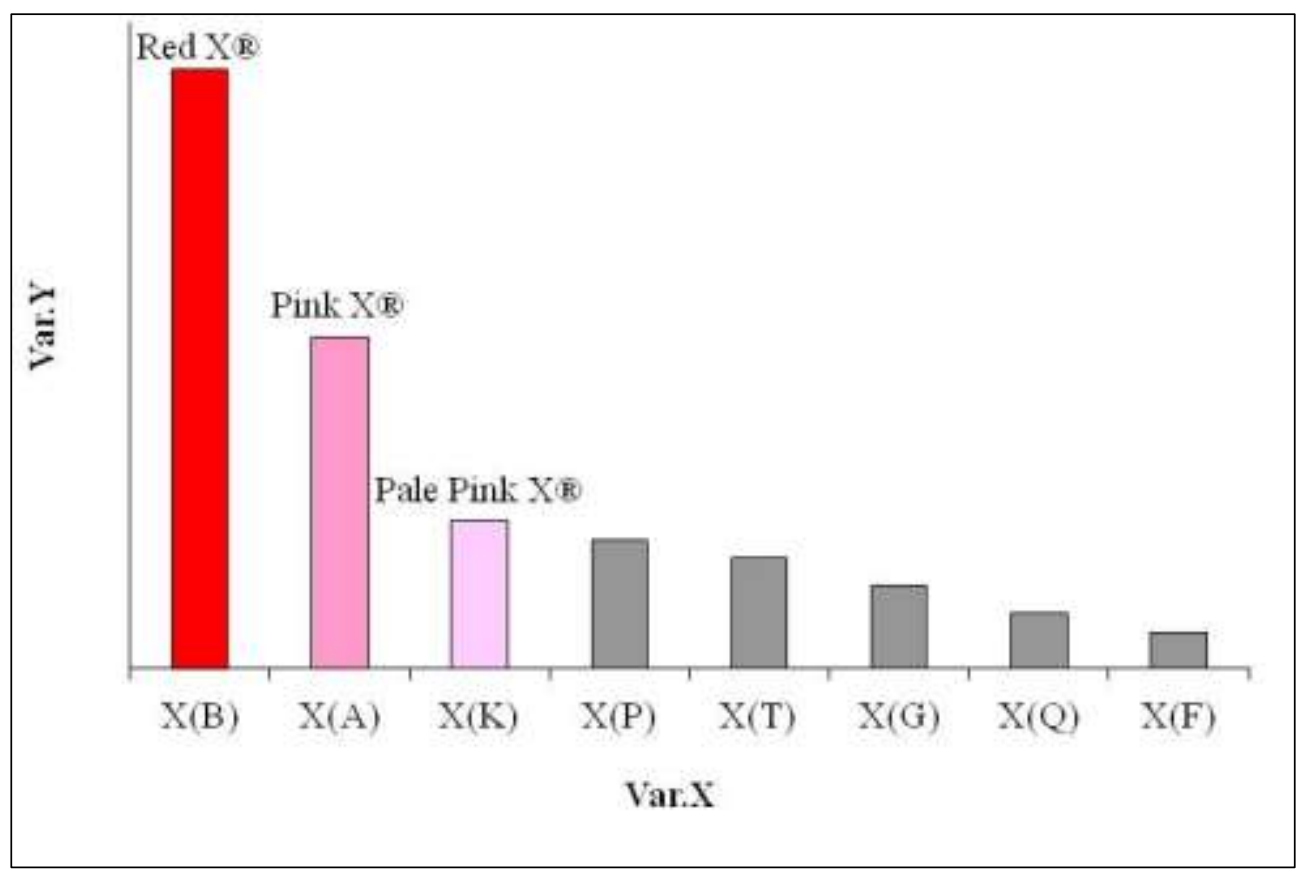

Figure $2-\operatorname{Red} X ®$ paradigm

The problem-solving roadmap is called FACTUAL ${ }^{\mathrm{TM}}$ : Focus, Approach, Converge, Test, Understand, Apply, Leverage (Table 1, adapted from Shainin, 2012).

Table 1 - Shainin roadmap: FACTUAL ${ }^{\mathrm{TM}}$

\begin{tabular}{|c|c|}
\hline Focus & $\begin{array}{l}\text { - Transformation of a business case into a technical project } \\
\text { - Project Definition }\end{array}$ \\
\hline Approach & $\begin{array}{ll}\text { - } & \text { Green } \mathrm{Y}^{\circledR} \text { Identification and Description } \\
\text { - } & \text { Development of Investigation Strategy } \\
\text { - } & \text { Measurement System Verification }\end{array}$ \\
\hline Converge & $\begin{array}{ll}\text { - } & \text { Converging on } \operatorname{Red} X^{\circledR} \\
\text { - } & \text { Compare best and worst case } \\
\text { - } & \text { RedX }{ }^{\circledR} \text { Candidate Identification }\end{array}$ \\
\hline Test & $\begin{array}{ll}\text { - } & \text { RedX } X^{\circledR} \text { Confirmed by Trial/DOE } \\
\text { - } & \text { Risk Assessment } \\
\end{array}$ \\
\hline Understand & $\begin{array}{ll}\text { - } & \text { Green } \mathrm{Y}^{\circledR} \text { to Red } \mathrm{X}^{\circledR} \text { Relationship Understood } \\
\text { - } & \text { Understanding of interactions } \\
\text { - } & \text { Customer requirements translated into limits } \\
\text { - } & \text { Appropriate Tolerance Limits Established }\end{array}$ \\
\hline Apply & $\begin{array}{l}\text { - } \text { Corrective Action Implemented and Verified } \\
\text { - } \quad \text { Procedures updated } \\
\text { - } \text { Green } \mathrm{Y}^{\circledR} \text { monitoring }\end{array}$ \\
\hline Leverage & $\begin{array}{ll}\text { - } & \text { Lessons Learned taken } \\
\text { - } & \text { Benefits Calculated }\end{array}$ \\
\hline
\end{tabular}

ISSN 1335-1745 (print) ISSN 1338-984X (online) 
The Shainin toolbox consists of roughly 30 techniques and tools - the wellknown as well as newly developed techniques - which create the comprehensive step-by-step system for process improvement (Shainin, 1993; Bhote and Bhote, 2000).

The $\operatorname{RedX}^{\circledR}$ paradigm is one of the cornerstones on which the Shainin $\operatorname{RedX}{ }^{\circledR}$ system as the problem-solving methodology stands (Shainin, 1993):

- For every effect there is dominant root-cause.

- The fastest way to identify the root-cause is through a search using empirical data and a progressive elimination process

- The tool used needs to be kept rigorously logical and statistically simple.

\section{METHODOLOGY}

Leading companies in the automotive industry are always searching for an efficient tool to reduce process variation. If we looked at problem-solving from the perspective of a top manager we would identify two main deficiencies of Six Sigma: projects are frequently time consuming and too often do not bring the expected results. In addition there are cases where the project failed completely.

\subsection{Task domain method}

Why is Six Sigma not effective as a method of reducing process variation? Firstly, this question should probably not even be raised as Sigma methodology was originally developed as an algorithm to reduce variation in manufacturing processes. This means Six Sigma was originally developed as a task domain method for variation reduction, nevertheless the scope of the method changed over time and Six Sigma became a general problem-solving method (de Mast and Lokkerbol, 2012). In principle task domain methods are more powerful than general. To summarize the current status of Six Sigma: the robust method for the reduction of process variation became less powerful and it led to the situation whereby Six Sigma methodology in the latest development stage could have certain limitations regarding the applicability of the method in the process variation field.

Shainin methodology is used for the reduction of process variation and solving of technical problems, so the methodology has a task domain character. It is clearly defined step-by-step problem-solving methodology. Such a type of problemsolving is called checklist stream and concerns highly structured problems which are solved by following a predefined algorithm (de Mast and Lokkerbol, 2012). Shainin, Kepner-Tregoe problem-solving methodology or Statistical Engineering (Steiner and MacKay, 2005) are examples of such a problem-solving approach. 


\subsection{Diagnostic process}

The efficiency of the diagnostic process depends greatly on the search strategy used. Shainin and Six Sigma are examples of the diagnostic strategy called branch-and-prune (de Mast, 2011). Branch-and-prune strategies struggle between the large divergence of the search space and the effort to converge the root-cause candidates into a dominant root-cause. We can use the example of the fishbone diagram: the search space is described by the hierarchical tree and the problem solver works to prune branches by the elimination of root-cause candidates.

Six Sigma uses a divergent cause $(\mathrm{X})$ to effect $(\mathrm{Y})$ approach in the diagnostic process which is based on iterative procedure: repeated identification of the potential root-cause, the generation of the root-cause hypothesis and consequent statistical testing to confirm whether the potential root-cause - input X - has a contribution to effect (Y). Most of the Six Sigma problem-solving projects start with the generation of potential root-causes using brainstorming visualized by the fishbone diagram. However there is no effective elimination method defined within Six Sigma to narrow down the list of root-cause candidates, there is in fact no algorithm to eliminate potential root-causes in terms of a step-by-step procedure which could be followed by the problem solver as a guideline apart from the general DMAIC framework. This makes Six Sigma very dependent on the skills and experience of the problem solver. In the case of a large search space described by an extensive fishbone diagram we can end up with very time consuming team sessions in order to eliminate every root-cause hypothesis.

In the Shainin System ${ }^{\mathrm{TM}}$ the progressive search and convergent strategy is used to identify the potential root-causes (Xs). The potential root-causes - the so called RedX ${ }^{\circledR}$ candidates - are tested using efficient confirmation methods, usually the full factorial Design of Experiments (DOE). We can use the full factorial DOE because the quantity of potential root-causes will be significantly reduced by the elimination method in previous stages. The strategy of elimination and zooming in is defined and tracked by a tool called Solution Tree ${ }^{\mathrm{TM}}$ (Figure 3). This tool will guide the problem solver through the whole problem-solving task. Solution Tree ${ }^{\mathrm{TM}}$ is, from a documentation point of view, a living document which is being updated with every step performed during a problem-solving project. The defined strategy is reviewed after each single task is completed and it supports problem-solving activities by keeping the right focus. 


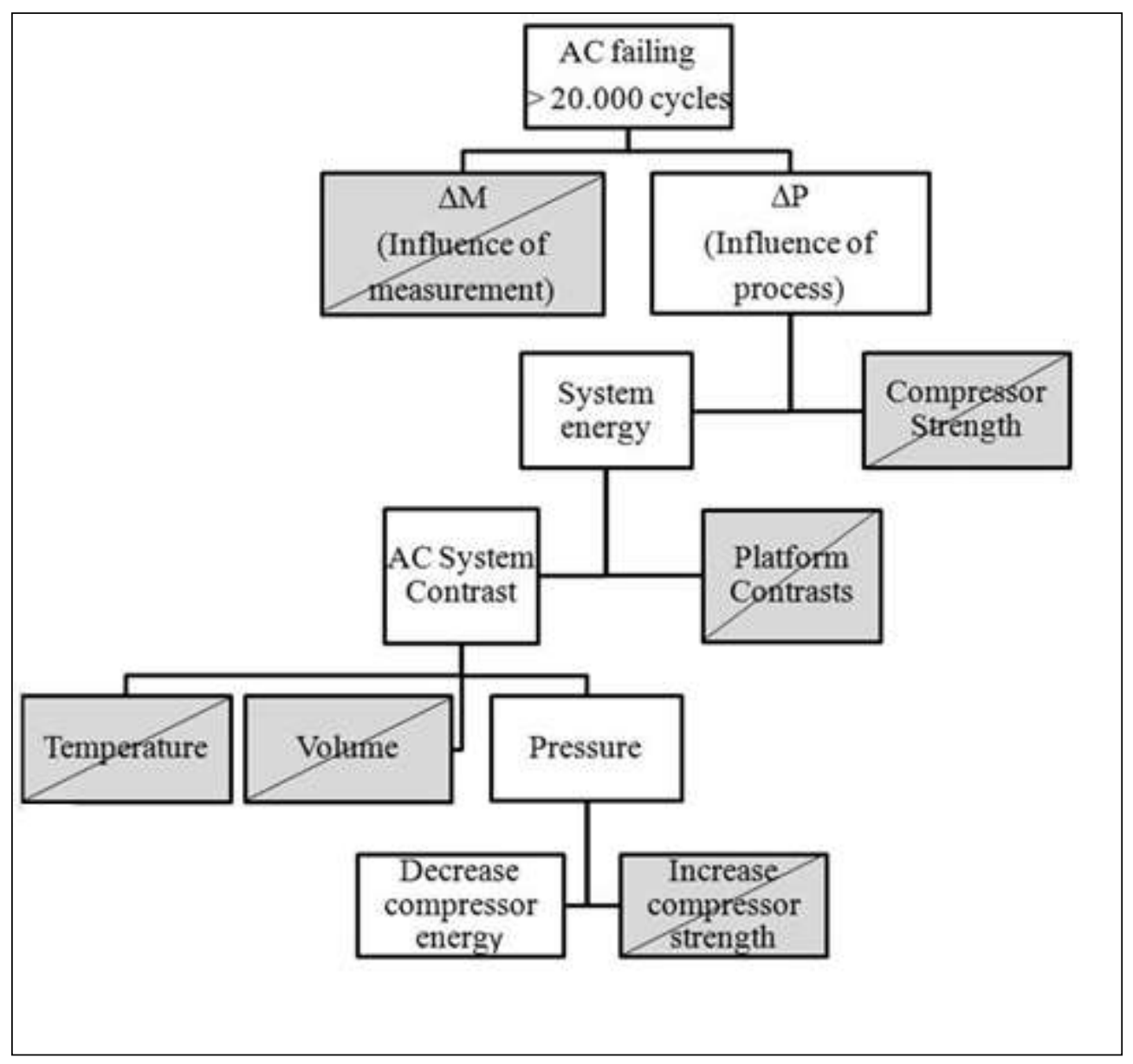

Figure 3 - Solution Tree ${ }^{\mathrm{TM}}$ (Shainin, 2008)

Deep understanding of the problem - advanced domain knowledge - is very important in solving problems using Shainin RedX ${ }^{\circledR}$ methodology; the importance of domain knowledge is emphasized. Understanding the physical and functional structure of the system as well as fault knowledge is the key to successful problem-solving. Contrary to the Shainin System ${ }^{\mathrm{TM}}$ the importance of domain knowledge is not well understood in the case of Six Sigma methodology.

The key difference between Shainin $\operatorname{RedX}^{\circledR}$ strategy (FACTUAL ${ }^{\mathrm{TM}}$ ) and Six Sigma methodology (DMAIC) is the Approach phase. This is the phase in which the problem-solving team develops a strategy based on understanding the failure symptom, measurement system performance and contrast between a good and bad product.

\subsection{More efficient Six Sigma}

Looking at the previous analysis, Shainin $\operatorname{Red} \mathrm{X}^{\circledR}$ methodology seems to be more suitable for problem-solving compared to Six Sigma. The use of the entire Shainin $\operatorname{RedX}^{\circledR}$ methodology in both the diagnostic and remedial journey is certainly an option, though according to Steiner, MacKay and Ramberg (2008) 
methodology is very strong in the diagnostic journey but weak in the remedial journey.

There are two main points to be modified in the current Six Sigma structure in order to make Six Sigma more efficient: to give Six Sigma more task domain character and to establish Six Sigma methodology as a checklist problem-solving method. This is, in combination with the use of the Shainin tools in the diagnostic journey, certainly a way of acquiring an effective problem-solving tool. To apply the Shainin RedX $X^{\circledR}$ tool box effectively we can use key tools to create a "Shainin backbone" which will be implemented within the Six Sigma framework (Figure 4):

- Solution Tree ${ }^{\mathrm{TM}}$ (Shainin, 2008)

- Multi-vari chart (Shainin, 2007)

- Isoplot ${ }^{\circledR}$ (Steiner, MacKay and Ramberg, 2008)

- Component Search ${ }^{\mathrm{TM}}$ (Steiner, MacKay and Ramberg, 2008)

- Variable Search ${ }^{\mathrm{TM}}$ (Dasgupta, Adiga and Jeff Wu, 2011)

- Rank Order Anova ${ }^{\mathrm{TM}}$ (Shainin and Shainin, 1990)

- Full factorial analysis: B vs. C (Better versus Current) or B vs. W (Best versus Worst) (Steiner, MacKay and Ramberg, 2008) 


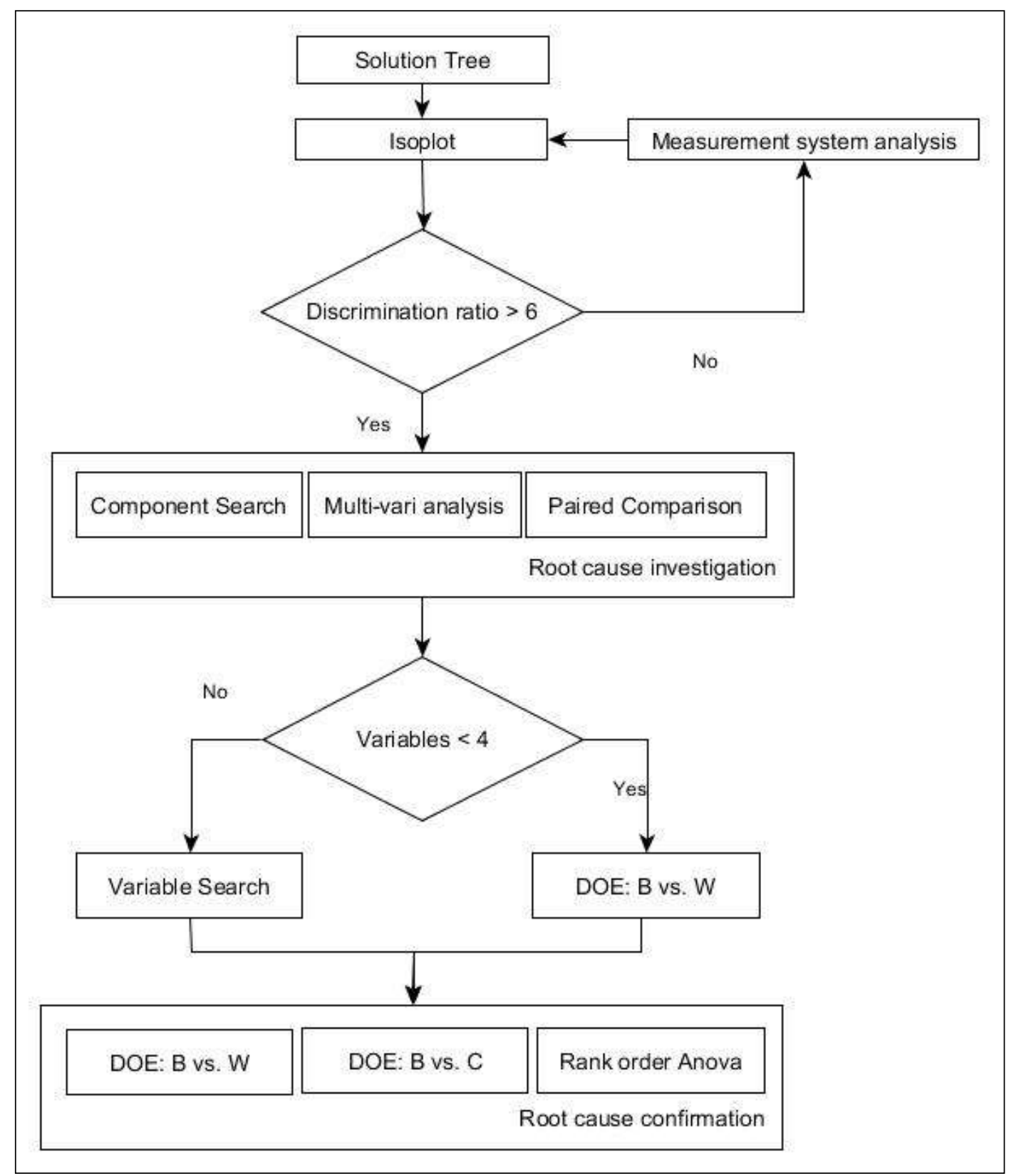

Figure 4-Key Elements of Shainin Red $X^{\circledR}$ methodology in the diagnostic phase

At first we should implement a tool which allows us to create and control the strategy of the problem-solving project - Solution Tree ${ }^{\mathrm{TM}}$ - flowchart which guides the problem-solving team through the case in question. This will ensure that the elimination process within Six Sigma is implemented and followed. The application of a progressive search (Shainin, 1993) and selected tools will lead to the strengthening of the Six Sigma toolbox (Sharma and Chetiya, 2009).

A root-cause investigation cannot be efficient without a reliable measuring system. Isoplot ${ }^{\circledR}$ is a tool used within Shainin $\operatorname{RedX} X^{\circledR}$ methodology for the quick evaluation of the measuring system as well as for the comparison of relative size of variation coming out of the process and measurement system family of variation (Steiner, MacKay and Ramberg, 2008). The simplest application is to 
measure a set of samples twice using the same measuring system and to evaluate the discrimination ratio between the variation coming from process $\Delta \mathrm{P}$ and the variation of the measuring system $\Delta \mathrm{M}$ (Figure 5).

Discrimination ratio $=\frac{\Delta P}{\Delta M} \geq 6$

In the case that an analysis using Isoplot ${ }^{\circledR}$ fails it is recommended to perform a full MSA prior to further decision taking.

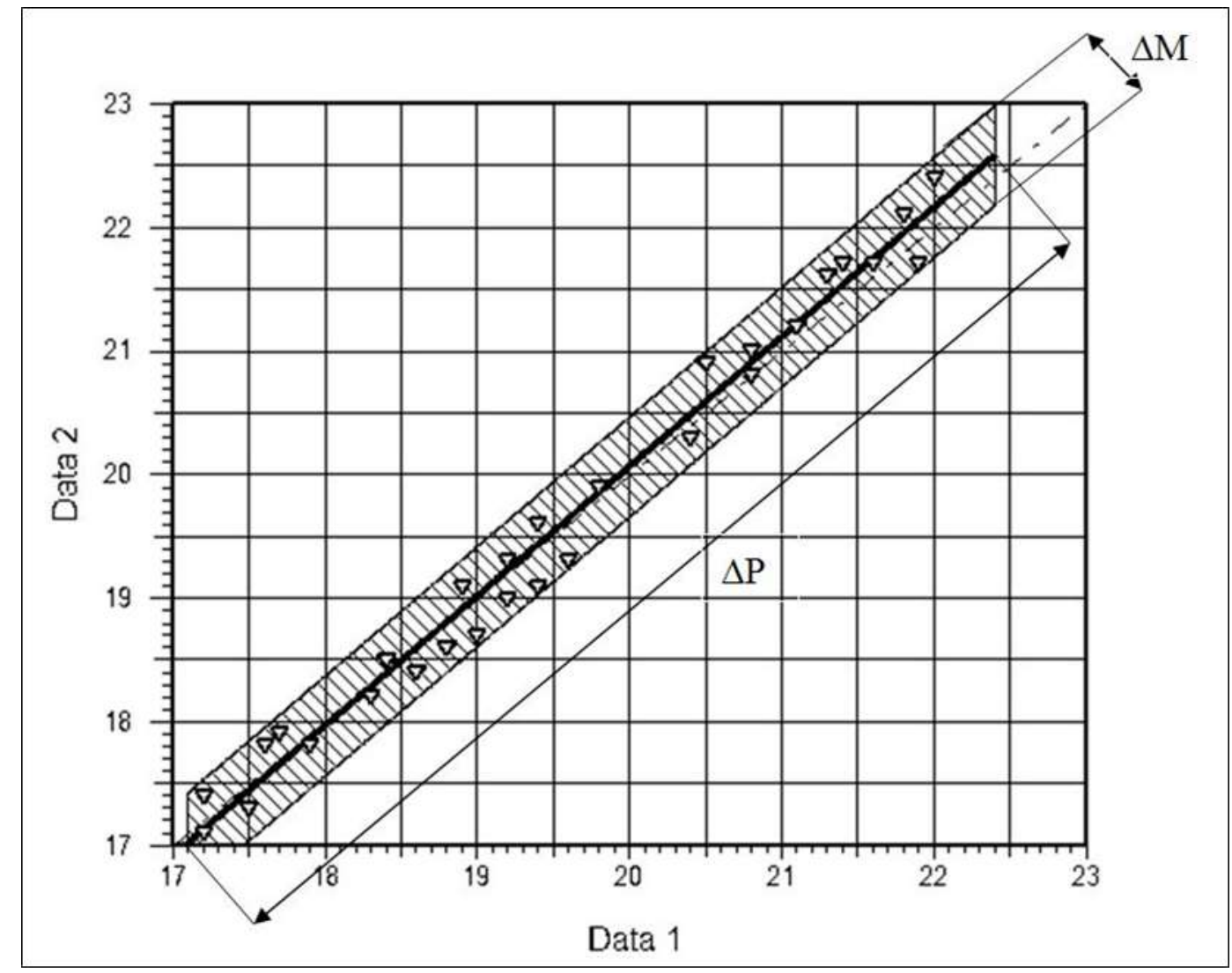

Figure 5 - Analysis of the measurement system using Isoplot ${ }^{\circledR}$

The aim of the diagnostic journey is to reduce the number of potential rootcauses, to detect the dominant root-cause and to confirm that the detected rootcause is actually the dominant one. The full factorial experiment is an effective tool for confirming the root-cause but we must ensure the number of the suspected variables is reduced by the elimination process to 2-4 variables. The most often used full factorial experimental plan within Shainin is the six-pack test (Bhote and Bhote, 2000) which tests three units produced under current (C) and better (B) conditions. The dominant cause is verified only in the case that all 3Bs achieve better output than all 3Cs.

The proposed integration of the key Shainin tools within the Six Sigma DMAIC roadmap is shown in Table 2. 
Table 2 - Integration of Shainin tools within Six Sigma DMAIC

\begin{tabular}{|c|c|}
\hline Define & $\begin{array}{l}\text { - Define the customers and their "Critical To Quality" characteristics (VOC) } \\
\text { - Define the business processes that are involved (VOB) } \\
\text { - Define the parameters critical to the process (VOP) } \\
\text { - Create a process map } \\
\text { - Decide on the metrics. } \\
\text { - Identify outputs Y. Define Green } Y^{\circledR} \\
\text { - Form a project team and develop a project charter } \\
\text { - Evaluate potential financial savings of the six sigma project }\end{array}$ \\
\hline Measure & $\begin{array}{l}\text { - Create a strategy of root-cause analysis (using Solution Tree }{ }^{\mathrm{TM}} \text { ) } \\
\text { - Validate measurement system: } \\
\quad \text { ○ Initial measurement system analysis using Isoplot }{ }^{\circledR} \\
\quad \text { Deeper MSA using gauge R\&R if necessary } \\
\text { - Collect data related to the process or product } \\
\text { - } \quad \text { Identify potential Xs: Talk to parts to understand the contrasts - difference } \\
\text { between extremes (BOB/WOW) } \\
\text { - Measure Ys in case there is not enough data available from running the } \\
\text { - } \quad \text { process }\end{array}$ \\
\hline Analyze & $\begin{array}{l}\text { - Identify the sources of variation } \\
\circ \quad \text { Start the clue generation: using a Component } \text { search }^{\mathrm{TM}}, \text { Multi-vari } \\
\text { chart, Concentration diagram } \\
\circ \quad \text { Isolate the root-cause using Variable search }{ }^{\mathrm{TM}} \text { or full factorial DOE } \\
\circ \quad \text { Confirm the root-cause by full factorial analysis or Rank Order } \\
\text { ANOVA } \\
\text { - Gap analysis between current and required performance } \\
\text { - Decide on processes to be improved }\end{array}$ \\
\hline Improve & $\begin{array}{l}\text { - Propose solutions } \\
\text { - Perform pilot studies, design of experiments etc. to evaluate proposed } \\
\text { - } \text { solution } \\
\text { - Implement changes and prove effectiveness }\end{array}$ \\
\hline Control & $\begin{array}{l}\text { - Implement controls to ensure improvement has been achieved and is stable } \\
\text { - Develop procedures and train the staff } \\
\text { - Update the control plan, FMEA and related quality documentation } \\
\text { - Evaluate the financial savings of the Six Sigma project } \\
\text { - Define the feedback loop }\end{array}$ \\
\hline
\end{tabular}

\section{CONCLUSION}

The purpose of the article is to propose the modification of Six Sigma methodology in order to achieve the improved efficiency of DMAIC using some approaches of Shainin $\operatorname{RedX}{ }^{\circledR}$ methodology in the diagnostic phase. The analysis of the Six Sigma diagnostic journey leads to the conclusion that Six Sigma lost its task domain character and the diagnostic process does not provide efficient support to a problem solver in terms of eliminating the root-cause candidates. The proposal to use alternative methodology - Shainin $\operatorname{Red} X^{\circledR}$ methodology - 
comes from comparing both methods. The Shainin System ${ }^{\mathrm{TM}}$ is a task domain method based on a convergent approach to investigation (from output to input). The knowledge of the system under investigation, subcomponents, production process as well as knowledge of the failure mechanism is a crucial precondition of Shainin RedX ${ }^{\circledR}$ methodology. The lack of task domain character as well as weakness in the diagnostic processes can be covered by the implementation of the Shainin key elements within a Six Sigma DMAIC framework. The key elements are the problem-solving strategy and progressive search which will lead to the identification and effective elimination of root-cause candidates and confirmation of the detected dominant root-cause. The proposed algorithm is intended to be strong for the diagnostic journey. In particular, the way of looking for a dominant root-cause should be less time consuming as the elimination steps will lead to a shortlist of potential dominant root-causes. The application of Shainin tools could simplify the toolbox as these tools are generally statistically simple with small sample plan sizes, mostly based on graphical tools and nonparametric tests that can be performed by hand.

Finally we should answer the question raised in the title of this article. Is Shainin methodology an alternative or an effective complement to Six Sigma? I do not think we would find a clear cut answer here. The experience from the industrial environment would probably lead to a very positive feedback regarding the Shainin System ${ }^{\mathrm{TM}}$ as this methodology is very strong in the diagnostic journey. However there are surely companies which would prefer the application of Shainin $\operatorname{RedX} X^{\circledR}$ methodology just as it is. The disadvantage of this methodology rests in a certain confidentiality of the methodology which prevents wider deployment. The proposed modification of the Six Sigma framework could be the right option to combine the benefits of both methodologies.

\section{REFERENCES}

Bhote, K.R., Bhote, A.K., 2000. World Class Quality. 2nd ed. New York: American Management Association, 512 p., ISBN 0-8144-0427-8.

Bovenzi, P., Bender, D., Bloink, R., Conklin, M., Abrahamian, J., 2010. Risk Reducing Product and Process Design During New Product Development. Warrendale, SAE International, 2010, 8 p., ISSN 0148-7191.

Dasgupta, T., Adiga, N., Jeff Wu, C.F., 2011. Another Look at Dorian Shainin's Variable Search Technique. Journal of Quality Technology, 43(4), pp.273-287.

de Mast, J., 2011. The tactical use of constraints and structure in diagnostics problem-solving. Omega, 39(6), pp.702-709.

de Mast, J., Lokkerbol, J., 2012. An analysis of the Six Sigma DMAIC method from the perspective of problem-solving. International Journal of Production Economics, 139(2), pp.604-614. 
Juran, J.M., De Feo, J.A., 2010. Juran's Quality Handbook. 6th ed., New York: McGraw-Hill Professional, 2010, 1136 p., ISBN 978-0-07-162973-7.

Linderman, K., Schroeder, R.G., Zaheer, S., Choo, A.S., 2003. Six Sigma: a goal theoretic perspective. Journal of Operations Management, 21(2), pp.193-203.

Schmidt, M., 2012. General Motors Technical Problem - Solving Group Drives Excellence, Case Study. American Society for Quality, November 2012, 6 p., Available at: http://asq.org/2012/11//general-motors.html.

Shainin, D., Shainin P.D., 1990. Analysis of Experiments. ASQC Quality Congress Transactions, San Francisco, 44, pp.1071-1077.

Shainin, R.D., 1993. Strategies for Technical Problem-solving. Quality Engineering, 5(3), pp.433-448.

Shainin, R.D., 2007. Multi-Vari Charts. In: F. Ruggeri, ed. 2007. Encyclopedia of Statistics in Quality and Reliability. London: Wiley, 1800 p., ISBN 978-0-47001861-3.

Shainin, R.D., 2008. How Lean Is Your Six Sigma Program?, Six Sigma Forum Magazine, 7(4), pp.42-45.

Shainin, R.D., 2012. Dorian's Statistical Engineering. ASQ's World Conference on Quality and Improvement, Anaheim, 21-23 May 2012, Vol. 66, pp.1-17.

Sharma, S., Chetiya, A.R., 2009. Simplifying the Six Sigma Toolbox through Application of Shainin DOE Techniques. Vikalpa, 34(1), pp.13-19.

Steiner S.H., MacKay R.J., 2005. Statistical Engineering: An Algorithm for Reducing Variation in Manufacturing Processes. Milwaukee: ASQ Quality Press, 2005, 716 p., ISBN: 0-87389-646-7.

Steiner, S.H., MacKay, R.J., Ramberg, J.S., 2008. An Overview of the Shainin System $^{\mathrm{TM}}$ for Quality. Quality Engineering, 20(1), pp.6-19.

Tosenovsky, J., Tosenovsky, F., Kudelka, O., 2013. Analysis of Robust Technology Design Methods. In: Conference proceedings $22^{\text {nd }}$ International Conference on Metallurgy and Materials Metal'2013, pp.1662-1667, ISBN 97880-87294-41-3.

Wortham, A., 2008. For Bosch, RedX marks spot for quality gains. Automotive News; February 2008, 82(6293), p.70.

\section{ABOUT THE AUTHOR}

Ing. Jan Kosina - external Ph.D. student VSB-Technical University of Ostrava, Faculty of Metallurgy and Materials Engineering, Department of Quality Management, Czech Republic. Doctoral study is supervised by prof. RNDr. Josef Tosenovsky, CSc., e-mail: kosinajan70@seznam.cz 